\title{
Bartleby o la política del caos ${ }^{\star}$
}

\author{
Andrés Camilo Torres Estrada**
}

\begin{abstract}
Recibido: 5 de febrero de 2013
Evaluado: 14 de abril de 2013

Aceptado: 30 de abril de 2013
\end{abstract}

\section{Resumen}

El artículo presenta un análisis del cuento de Herman Melville: "Bartleby, el escribiente". Este análisis parte de un acercamiento a la literatura desde una noción de política inspirada en autores como Jacques Derrida y Jacques Rancière, pero que se aparta de esta filosofía cuando, por encima del propio texto y sus posibilidades, se pretende encontrar en él heterotopías, esperanzas y comunidades por venir. Esta noción de política acerca a la literatura al mundo efectivo, transfigurando los modos de ser y no ser. Así, el personaje de Bartleby se presenta en medio del mundo de la representación como un agente del caos. En esto consiste la política del escribiente: su incursión devela las farsas del mundo construido y soñado por los hombres; pero esta destrucción que causa es inútil: el mundo de la representación ha sentido su absurdo, no sabe qué hacer con dicho agente del caos, pero no es suficiente para arruinarlo. Bartleby, quien se ha indeterminado y ha abandonado las dualidades de ser y no ser, tampoco puede seguir viviendo: ya no hay espacio para la vida sin referencias en un mundo humano y ficticio.

Palabras clave: Bartleby, política, literatura.

* Artículo de reflexión a partir de la tesis de maestría Borges, Bartleby o la política del caos, presentada en la Universidad de los Andes en diciembre de 2012.

** Magíster en Literatura de la Universidad de los Andes. Correo electrónico: ac.torres410@uniandes.edu.co 


\section{Bartleby, or chaos and politics}

\section{Abstract}

The paper presents an analysis of the story of Herman Melville "Bartleby, the Scrivener". This analysis is based on an approach to literature from a political notion inspired by authors such as Jacques Derrida and Jacques Rancière, but deviates from this philosophy when, above the text itself and its possibilities, it is pretended to find in it heterotopias, hopes and communities to come. This notion of politics gets literature closer to the actual world, transfiguring the ways of being and non-being. Thus, the character of Bartleby comes amid the world of representation as an agent of chaos. That is what the politics of the scrivener is about: his incursion unveils the farces of the world built and dreamed by men, but the destruction it causes is futile: the world of representation has felt its absurdity and does not know what to do with the agent of chaos, but it is not enough to ruin it. Bartleby, who has been undetermined and has left the dualities of being and not being cannot continue living: there is no room for life without references in a human and fictional world.

Keywords: Bartleby, politics, literature. 


\section{Bartleby ou a política do caos}

\section{RESUMO}

Recibido: 5 de febrero de 2013

Evaluado: 14 de abril de 2013

Aceptado: 30 de abril de 2013
O artigo apresenta uma análise do conto de Herman Melville, "Bartleby, o el Escribiente". Esta análise baseia-se numa abordagem à literatura a partir de uma noção política inspirada em autores como Jacques Derrida e Jacques Rancière, mas desvia-se desta filosofia, quando, por cima do próprio texto e de suas possibilidades, pretendem-se achar nele heterotopias, esperanças e comunidades por vir. Esta noção de política aproxima à literatura ao mundo real, transfigurando os modos de ser e não ser. Assim, o personagem de Bartleby apresenta-se no meio do mundo da representação como um agente do caos. Nisto consiste a política do escrivão: sua incursão revela as farsas do mundo construído e sonhado pelos homens, mas esta destruição que causa é inútil: o mundo da representação sentiu seu absurdo, não sabe o que fazer com dito agente do caos, mas não é suficiente para arruiná-lo. Bartleby, quem tem-se indeterminado e tem abandonado as dualidades de ser e não ser, também não pode continuar a viver: já não há espaço para a vida sem referências num mundo humano e imaginário.

Palavras-chave: Bartleby, política, literatura. 
I

People see all the time, and they just can't remember how to act.

Bob Dylan, Idiot Wind

Casi desapercibido por su generación, Herman Melville fue rescatado en el siglo XX como uno de los autores norteamericanos más importantes del siglo anterior. Moby Dick hace ya parte de los clásicos de la literatura, y dentro de la obra de Melville hay un personaje que ha llamado la atención de una gran cantidad de autores: Bartleby. "Bartleby, el escribiente", un cuento de 1853, narra la historia de un extraño escribiente en Walt Street. Maurice Blanchot, Jacques Derrida, Gilles Deleuze y Jacques Rancière, gran parte de la filosofía francesa contemporánea, le han dedicado varias páginas. Giorgio Agamben, Jorge Luis Borges y Enrique Vila-Matas se unen a los asombrados por el escribiente, entre otros. Mucho se ha dicho al respecto.

Digamos que lo que podría llamarse sencillamente mi "propuesta de lectura" sobre el cuento, la que haré en el presente texto, implica necesariamente una manera de concebir la literatura y de ser en el mundo. Es lo que llama la atención de la palabra política del título, que puede llegar a confundir: la literatura, profunda y orgullosamente inútil dentro del mundo de la representación, produce ciertas implicaciones que transfiguran los modos de ser y no ser, de relacionarse con los otros y con el mundo. No se escribe inocentemente. Bartleby es un agente del caos, destructor del mundo de la representación (y de la literatura, claro, que pertenece a ese mundo); destrucción exitosa o fracasada, ese no es el asunto todavía.
Esta noción de política está cercana a la que filósofos como Rancière, Derrida y Deleuze han atribuido a la literatura. De esta noción me interesa, principalmente, la diferenciación que se hace con política como término asociado a una específica rama de la sociedad (una política partidista, por ejemplo; una política que pertenece únicamente a "los políticos"). Digamos que los estudios literarios han utilizado con más insistencia la noción de poética o estética. La concepción de política que atraviesa este trabajo se acerca a lo que se ha entendido por esas mismas nociones, pero he preferido la de política por sus implicaciones en las maneras de ver y ser. Aquí también parto de una noción clara de literatura: quien habla de poética o estética generalmente mantiene al arte dentro de una esfera académica; es decir, se lee para encontrar coincidencias, repeticiones, fallas, virtudes, etc., dentro del ámbito puramente literario. Hablar de política, en cambio, reivindica cierta disposición del lector (que no es precisamente una disposición del todo previa ni consciente) de ser transfigurado en sus modos más propios y que definen su ser en el mundo. Hablar de poética apela al mundo de la representación que se ignora como tal y se mantiene en el juego de las dualidades y referencias; hablar de política involucra el cuestionamiento de ese mundo hasta develar, desde lo más profundo, su construcción y terminar por descubrirse y hasta condenarse.

Me aparto, sin embargo, de cierta tendencia de estas filosofías en las que coinciden, aunque sus métodos y sus acercamientos a la literatura sean diferentes. Estoy hablando de los espacios de indeterminación que estos filósofos han querido encontrar en la literatura donde es posible rechazar el mundo de 
la representación. Lo suficientemente aguda como para no creer en una verdadera actualización de estos espacios, esta filosofía ha buscado en cierta literatura una promesa que no se realiza, un secreto que no se revela, donde lo indeterminado puede llegar a consumarse. En Deleuze y Agamben podremos verlo en su actitud frente a Bartleby, a partir de quien han creado una esperanza para un tipo de comunidad libre del mundo de la representación.

Esta esperanza que deviene inevitablemente en optimismo es lo que no he encontrado en el cuento de Melville. El optimismo no solo se diferencia del pesimismo en sus visiones de mundo, sino también en su manera de surgir. El optimismo, por lo general, no aparece como consecuencia de cierta investigación, sino que es una manera previa de enfrentarse a cualquier búsqueda. Se dice: "trato siempre de ser optimista"; y se agrega generalmente: "a pesar de las circunstancias". Un pesimista, por otro lado, lo es únicamente por las circunstancias, como resultado de su investigación. El pesimismo es un resultado, no un velo previo que se pone frente al mundo, sino $-\mathrm{y}$ aquí el caso más claro será siempre el de Schopenhauer - la conclusión que puede tenerse luego de haber observado el mundo. Jamás se oirá decir: "siempre trato de ser pesimista". El optimismo, para ser, parece siempre depender de una previa imposición. Quien ve esperanza en la literatura que revisa este trabajo, impone al texto algo que no le pertenece y parece querer gritar: ¡Ah, Bartleby! ¡Ah, humanity!, a la manera del ridículo abogado de la historia.

De esta manera, la política del caos es aquella literatura donde el mundo de la representación, desde sí mismo, comienza a desmoronarse, donde se devela como construcción y no deja espacio para ninguna forma de esperanza. En la política del caos, la transfiguración de los modos de ser y no ser llega a un espacio de imposibilidades: no se puede ser ni no ser. Esta noción de política y literatura rechaza cualquier otra que no sea la del caos. Otra política entraría en el mundo de la representación eligiendo alguna de sus posibilidades, manteniéndose en el sistema de referencias y dualidades. Solamente la política del caos es justa, en su más puro sentido: la no preferencia. Esta política no tiene proyecto después de la destrucción, no supone una salida, no promete una esperanza. Tiene un por qué, pero no un para qué. Intentaré reivindicar aquí para Bartleby un lugar de la desesperanza y, si se quiere, del desastre.

\section{II}

El "no esto más que aquello", el término técnico mediante el cual los escépticos expresaban su pathos más propio: la epoché, la suspensión. "Los escépticos - escribe Diógenes en la Vida de Pirrón - no usaban esta expresión en sentido positivo (theicós) ni negativo (anaireticós), pues, para refutar un argumento, decían: "No existe Escila más que la Quimera". Sin embargo, el término no se toma tampoco en sentido comparativo: "Los escépticos eliminan realmente hasta el mismo

'no más que', pues, así como la existencia de la providencia no es más cierta que su inexistencia, así también el 'no más que' no es más cierto que su negación" [...] Es imposible caracterizar con mayor precisión el modo en que el escribiente utiliza su obstinada fórmula.

Pero la analogía puede prolongarse en otra 
dirección [...] Sexto añade: "Y esto es lo más importante: al enunciar esta expresión, el escéptico dice el fenómeno y anuncia el pathos sin opinión alguna" [...] Cuando decimos

"todo es incomprensible", no intentamos afirmar que aquello que los dogmáticos buscan sea por naturaleza incomprensible, sino que nos limitamos a anunciar la pasión. Giorgio Agamben, "Bartleby o la potencia”

Para esbozar mi lectura, empezaré siguiendo el ensayo de Deleuze: "Bartleby o la fórmula". Resumamos rápidamente el texto del filósofo francés. Deleuze afirma que Bartleby destruye el doble sistema de referencias (donde opera la comunicación y la producción de sentido), que se aparta del sistema de presupuestos (que aquí, fiel a Schopenhauer, llamaré a estos sistemas "el mundo de la representación"). Su fórmula (I would prefer not to), aparentemente agramatical, abre un vacío en el lenguaje, además de desactivar los actos de habla:

\section{Cuando hablamos, no indicamos úni- camente cosas o acciones, sino que ejecutamos actos que nos garantizan ciertos vínculos con nuestros inter- locutores, según nuestras relaciones mutuas: ordenamos, preguntamos, prometemos, rogamos, emitimos "ac- tos de habla" (speech acts). Los actos de habla son autorreferenciales (yo doy efectivamente una orden al decir "Te orde- no..."), mientras que las proposiciones descriptivas se refieren a otras cosas o a otras palabras. Este doble sistema de referencias es el que Bartleby destruye (Deleuze, 2000, p. 66).}

A partir de esto, Deleuze busca integrar a Bartleby dentro del corpus de Melville y, principalmente, desde The Confidence-man, texto en el que el autor norteamericano esboza una teoría sobre la novela. De esta manera, Deleuze ubica al escribiente como un Original, un sujeto sin identidad ni lugar:

La ley, las leyes, gobiernan sobre una naturaleza sensible secundaria, pero hay seres innatamente depravados que participan de una Naturaleza primaria y suprasensible, originaria, oceánica, que persigue a través de las leyes su propia e irracional finalidad - la Nada, la Nada-, y que no conoce ley alguna (Deleuze, 2000, p. 75).

Deleuze (2000) deduce, entonces, una comunidad por venir configurada a partir de este tipo de sujetos, pero donde es esencial la descomposición de la función paterna: "Liberar al hombre de la función de padre, engendrar al hombre nuevo, al hombre sin particularidades, reunir la humanidad y la originalidad, constituyendo una sociedad de hermanos a modo de una nueva universalidad" (p. 83).

La primera línea del ensayo de Deleuze es llamativa en el momento de su relectura: "Bartleby no es una metáfora del escritor, ni el símbolo de nada" (p. 59). Es inevitable, entonces, recordar el final del ensayo: "De vocación esquizofrénica, y hasta catatónica y anoréxica, Bartleby no es un enfermo, sino el médico de una América enferma, el Medicine-man, el nuevo Cristo o el hermano de todos nosotros" (p. 92). En el cuento de Melville hemos visto que Bartleby es un escribiente, trabaja para un abogado, no hace más que copiar, y cuando se le pide algo diferente, responde: "Preferiría no hacerlo". Luego de un tiempo deja inclusive de 
copiar, hasta que lo llevan a la cárcel y muere allí. ¿Cómo es posible pensar en Bartleby como "nuevo Cristo o hermano de todos" y, al mismo tiempo, como símbolo de nada?

Ya Rancière, en "Deleuze, Bartleby, and the Literary Formula", había señalado esta inconsistencia a través de todo el ensayo de Deleuze. Este último asegura que la fórmula que lleva al lenguaje a sus límites responde a una operación performativa sobre el lenguaje mismo, que desactiva el doble sistema de referencias (también los símbolos, entendemos); sin embargo, en toda la segunda parte del ensayo, Deleuze olvida la fórmula para centrarse en el héroe (y todavía más problemático, en los héroes de Melville). La literalidad de la fórmula, su carácter performativo (y no simbólico), ha desembocado en un símbolo.

No obstante, es posible que solo se trate de un descuido. Tal vez la fórmula permita al personaje convertirse en el sujeto sin identidad ni lugar, y la crítica de Rancière exagere la disonancia entre la fábula y la literalidad. Miremos cómo ha llegado Deleuze de un lado a otro, de la fórmula a la política de la comunidad de hermanos sin padre. Deleuze supone que la reacción de Bartleby, su primer y sucesivos "preferiría no hacerlo", se deben a un pacto que el abogado (el padre) ha roto:

El pacto consistía en lo siguiente: Bartleby copiaría junto a su jefe, que podría escucharle pero no verle, como un ave nocturna que no soporta la mirada. Entonces, sin duda, cuando el abogado (sin hacerlo siquiera explícito) quiere sacar a Bartleby de su biombo para corregir las copias con los otros escribientes, viola el pacto (Deleuze, 2000, pp. 70).

¿De dónde viene esta suposición (que líneas después se convierte en "sin duda") de Deleuze? Si el abogado es el hombre que acude a la razón (el clímax del cuento llega cuando Bartleby responde: "Por ahora prefiero no ser un poco razonable" [Melville, 2008, pp. 71]), a la filantropía ("Sí, puedo adquirir a muy bajo precio la deleitosa sensación de amparar a Bartleby; puedo adaptarme a su extraña terquedad; ello me costará poquísimo o nada y, mientras, atesoraré en el fondo de mi alma lo que finalmente será un dulce bocado para mi conciencia" [p. 51]), a la voluntad ("¿No quiere?", pregunta el abogado al menos dos veces, además de encontrar consuelo en "Edwards on the Will"), a las suposiciones ("Era una bella idea, dar por sentada la partida de Bartleby" [p. 81]), a la amistad ("¿Pero qué objeción razonable puede tener para no hablar conmigo? Yo quisiera ser su amigo" [2008, pp. 69]), al deber ("¿Qué debo hacer?, ¿qué dice mi conciencia que debería hacer con este hombre, o más bien, con este fantasma?" [p. 93]), y, en fin, si el abogado acude a todas las referencias humanas que se le ocurren, ¿qué lo diferencia a él, el padre, de Deleuze, quien parece no estar muy lejos cuando acude al pacto violado entre hombres, para darle una razón a la actitud de Bartleby?

Este es un momento decisivo en el ensayo en el que Deleuze afirma que la primacía paterna se diluye ante la respuesta originada por el pacto violado. Sin embargo, tiene que ir fuera del cuento para que su justificación nos parezca más convincente: no solo trae como referencias a Moby Dick y otros trabajos de Melville, sino inclusive 
a Kleist y a la literatura norteamericana. A partir de esto, Bartleby ha entrado a formar parte del grupo de personajes que participan de la naturaleza primaria. En su "nada de voluntad mejor que voluntad de nada" (Deleuze, 2000, p. 76), Bartleby, como los otros personajes, afirma Deleuze, "no pueden sobrevivir más que petrificándose, negando la voluntad, y esa suspensión les santifica" (p. 76). En otras palabras, Deleuze está afirmando: el abogado rompe el pacto con el escribiente, quien como respuesta solo puede petrificarse para sobrevivir. Tomemos a Deleuze literalmente, lo cual su ensayo nos lo permite (y hasta sugiere): si Bartleby no se petrificara, si no se hace el sujeto sin determinación, entonces moriría. Lo digo de nuevo: según Deleuze, Bartleby, dentro las referencias humanas, hace un pacto con su jefe; al ser "traicionado", debe abandonar ese sistema de referencias y "petrificarse" para sobrevivir. Admitamos que no hay en el cuento un pasaje que niegue rotundamente esta hipótesis. Pero digamos, por evidente que resulta, que no solo es imposible confirmarla (y no es esta la cuestión que complejiza el asunto), sino que es muy difícil imaginarla.

¿Podemos pensar, realmente, que toda la actitud de Bartleby surge a partir de un pacto violado? Aunque sea probable (poco probable), lo que extraña es que el escribiente, camino a la indeterminación, se prestara para un juego de referencias humanas, del mundo de la representación. Y todavía más problemático: ¿podemos pensar, realmente, que la "petrificación" es un método de supervivencia? El cuento desmiente este principio (y Deleuze dará cuenta de ello, ya veremos) cuando al final, en el clímax de su indeterminación, cuando ha dejado incluso de copiar y hasta de comer, cuando está completamente petrificado, Bartleby muere. ¿No parece más acertado pensar que es precisamente esa petrificación lo que lleva al escribiente a la muerte? El cuento al menos lo sugiere así, no parece que haya alguna razón para esconder otro motivo.

Finalmente, Deleuze (2000) une toda esta interpretación con la visión de comunidad que ha visto en Melville:
¿Cuál es, pues, el problema más grave que atormenta a Melville en toda su obra? [...] Se trata, sin duda alguna, de reconciliar a los dos originales, pero para ello es preciso también reconciliar al original con la humanidad secundaria, lo inhumano con lo humano (p. 83).

Así, América parece ser el lugar de esa nueva comunidad, y Bartleby lo único que estaría esperando es una hermana para emprender su viaje (p. 89). “QQué pide Bartleby si no es un poco de confianza, mientras que el abogado le ofrece únicamente caridad y filantropía, todas las máscaras de la función paterna?" (p. 89). Confianza, dice el filósofo francés, como si un poco de confianza fuera diferente esencialmente de la caridad o la filantropía. Imaginemos, pues, lo que nos propone Deleuze; imaginemos que el día en que el abogado tiene que volver a la oficina (de la que ha huido) para tranquilizar a la gente y habla con Bartleby, entre las propuestas que le hace (volver a hacer copias, llevar los papeles de una tienda de ropa, ser camarero, viajar por todo el país, viajar a Europa, ir a vivir a la casa del abogado [Melville, 2008, pp. 101]), también el abogado podría proponerle a Bartleby un viaje con una hermana "con quien compartir su 
bizcocho de jengibre como una nueva hostia" (esta es realmente una cita literal del ensayo de Deleuze, por increíble que parezca [p. 89]). No estoy llevando al absurdo la idea de Deleuze; pongámoslo en otros términos: imaginemos, pues, que el abogado le brinda un poco de confianza, le dice que afuera hay un mundo dispuesto a la fraternidad y a ser una sociedad sin padres. Imaginemos cómo el rostro de Bartleby cambia y dice finalmente: sí, sí, acepto (o, al menos, eso preferiría). Hay que reparar en una cosa: Deleuze no está diciendo que la comunidad por venir sea un utópico lugar de originales, de hombres sin referencias; en cambio, es una comunidad donde el hombre sin referencias (el "inhumano", aunque al estar por fuera de la relación de humanidad, del mundo de la representación, considero más acertado llamarlo el "a-humano") convive con el mundo humano; es decir, el abogado le propondría a Bartleby un mundo donde los originales y los demás conviven, y él aceptaría.

No solo esta propuesta jamás llega, sino que además Deleuze (2000) entiende que Melville la concebía imposible: "Mucho antes que Lawrence, Melville y Thoreau diagnosticaron la enfermedad americana: el nuevo cemento que restablece el muro, la autoridad paterna y la inmunda caridad, Bartleby se deja morir en la cárcel” (p. 90). ¿Cómo es posible que luego de aceptarlo, el filósofo francés se empeñe en que el escribiente simboliza un pueblo futuro? Deleuze acepta que el cuento no es ese pueblo, pero parece pensar, realmente, que si las condiciones hubieran sido diferentes, Bartleby habría aceptado la imaginaria e insólita propuesta del abogado; que así, Bartleby nos habla de una posibilidad, de "una mutación humana" (p. 91). Estoy seguro de que el escribiente es una excepción de lo humano, que cuestiona todas las referencias, que escapa a todos los atributos, pero no veo cómo es posible, a partir del cuento, imaginar "los derechos de un pueblo futuro" (p. 91), porque Bartleby, además de rechazarlo todo, también ha rechazado eso.

\section{III}

Volvamos al cuento. Desde la primera página, el abogado nos advierte para qué tipo de lector es su historia:

He conocido a muchos [copistas], profesional y particularmente, y podría referir diversas historias que harían sonreír a los señores benévolos y llorar a las almas sentimentales. Pero a las biografías de todos los amanuenses, prefiero algunos episodios de la vida de Bartleby, que era uno de ellos, el más extraño que yo he visto o de quien tenga noticia (Melville, 2008, p. 21) ${ }^{1}$.

Luego advierte que para contar la historia de Bartleby, "conviene que registre algunos datos míos, de mis empleados, de mis asuntos, de mi oficina y de mi ambiente general" (2008, p. 21). Estas primeras páginas

1 Esta advertencia me recuerda inevitablemente una visión de la literatura que Borges esbozó alguna vez alrededor de la figura de Bernard Shaw: "El carácter del hombre y sus variaciones son el tema esencial de la novela de nuestro tiempo; la lírica es la complaciente magnificación de venturas o desventuras amorosas; las filosofías de Heidegger y Jaspers hacen de cada uno de nosotros el interesante interlocutor de un diálogo secreto y continuo con la nada o con la divinidad; estas disciplinas, que formalmente pueden ser admirables, fomentan esa ilusión del yo que el Vedanta reprueba como error capital. Suelen jugar a la desesperación y a la angustia, pero en el fondo halagan la vanidad; son, en tal sentido, inmorales" (Borges, 2001, p. 143). Parece que Melville, al menos en este cuento, se mantendrá alejado de esta literatura inmoral. 
donde efectivamente eso se nos cuenta no dejan de ser reveladoras. Se nos presenta, antes de que llegue el agente del caos, el mundo de la representación: el abogado convive con tres empleados bastante extraños, pero su extrañeza nos es presentada con cierta benevolencia. El propio abogado parece contradecirse bastante y cuenta con cierto afán de justificarse excesivamente ${ }^{2}$. El panorama de la oficina, el mundo de la representación, parece tender de un hilo ${ }^{3}$. Sin embargo, ese panorama se repite con tal constancia que es un orden, por extraño que pueda parecer. El abogado acepta ese mundo, como se acepta lo absurdo cuando se convierte en cotidiano; como se acepta la desorganización y se convierte en mandato. El mundo del abogado es un mundo de referencias construido (soñado) con más grietas que lo que permite generalmente un mundo de la representación.

¿Cómo se nos presenta Bartleby? El abogado nos recuerda la primera impresión de su figura "pálida y pulcra, respetable hasta inspirar compasión, con un aire irremediable de desamparo" (Melville, 2008, p. 37). Luego, su manera de trabajar: "Hacía turno doble, copiaba a la luz del día y a la luz de las velas. $[\ldots]^{4}$ Pero escribía en silencio,

2 Afirma sentir "que la vida más fácil es la mejor" (Melvillle, 2008, p. 21), pero el ambiente de su oficina no parece ser fácil para nada: dice no ser vanidoso, pero abunda en referencias sobre sí mismo; su condescendencia con el extraño comportamiento de sus empleados es justificada siempre en varias líneas.

3 Recuerdo de nuevo a Borges (1957): "Nosotros (la indivisa divinidad que opera en nosotros) hemos soñado el mundo. Lo hemos soñado resistente, misterioso, visible, ubicuo en el espacio y firme en el tiempo; pero hemos consentido en su arquitectura tenues y eternos intersticios de sinrazón para saber que es falso" (p. 136).

4 He omitido aquí el siguiente fragmento: "Yo, encantado con su aplicación, me hubiera encantado aún más si él hubiera sido un trabajador alegre" (Melville, 2008, p. 39). Esta preocupación me recuerda que también los sentimientos más nobles son creación del mundo pálidamente, mecánicamente" (p. 39). Aquí su reacción, luego del primer "preferiría no hacerlo": "La cara permanecía serena en su delgadez, el ojo gris oscuramente tranquilo. Ni la menor señal de turbación" (p. 43); y una vez más: "Preferiría no hacerlo - dijo, despacio y respetuosamente-" (p. 55).

Todas las referencias a su carácter y a su apariencia giran alrededor de estas. Resulta indudablemente extraño un personaje así. Pronto nos vamos dando cuenta de que estas características dadas por el abogado son problemáticas, que a él mismo parece costarle dar con las palabras para describirlo. La razón es sencilla: su comportamiento no solo es extraño, sino realmente fuera de los límites, fuera de las referencias, más allá de las orillas. El abogado dice: "Si hubiera habido en su actitud la menor incomodidad, enojo, impaciencia o impertinencia, en otras palabras si hubiera habido en él cualquier manifestación normalmente humana, yo lo hubiera despedido de forma violenta" (p. 43). No es "extraño" en oposición a "conocido", sino extraño, inclusive, por encima de esos opuestos. Bartleby es un hombre callado, pero ni siquiera se abandona por completo al silencio; se escapa también de la oposición entre hablar y callar. Todo esto ya lo ha reconocido Deleuze (2000): "Bartleby es el hombre sin referencias, sin posesiones, sin propiedades, sin cualidades, sin particularidades: demasiado llano como para que se le pueda adherir alguna particularidad.

de la representación. Es inexacta aquella ciencia ficción en la que los hombres del futuro son máquinas sin sentimientos que trabajan sin cesar y sin pensar. El mundo de la representación dominante actualmente no solo ha inventado la preeminencia del trabajo y el esfuerzo como virtudes aclamadas; también está muy preocupado por nuestros sentimientos, nuestra alegría. Acaso la felicidad no existía; tuvieron que inventarla para justificar el mundo. 
Sin pasado ni futuro, es instantáneo" (p. 68). La misma soledad de Bartleby es otra soledad que no se opone a la compañía, porque no hay posibilidad de que el escribiente deje de estar solo con hombre alguno.

Tenemos también su escape a todas las referencias a las que acude el abogado, ya citadas unas páginas atrás. Bartleby supera y renuncia tanto al principio de razón como al de voluntad, a toda condición de verdad como al principio de contradicción, y así a todas las ficciones humanas, a todo el mundo de la representación. Rompe las tablas de la ley, pero también toda tabla ${ }^{5}$. Corta el lazo con el padre, pero también todo lazo. No se revela ante un mundo injusto, moderno, donde no hay espacio para él. El escribiente renuncia a todos los mundos, justos o injustos, porque su lugar no existe, su espacio no hace parte de lo concebible, no es un espacio de los hombres. Deleuze parece advertir que esto implica su liberación, pero realmente no hay ninguna evidencia de que Bartleby se haya liberado. Ya no se rige por ninguno de esos principios, su "experimento" no tiene que ver con la verdad ni con el ser o no ser (“"... al liberarse del principio de razón, se libera tanto del ser como del no ser, creando su propia ontología" [Agamben, 2000, p. 119]), pero el peso del mundo humano arruina su indeterminación (o su pura potencia).

Bartleby, quien debía poder tanto como no poderlo todo, termina no pudiendo no morir en las circunstancias en que muere. Bartleby no fracasa por morir, sino porque

5 "Y no viene para traer unas nuevas tablas de la Ley, sino, como en las especulaciones cabalísticas acerca del reino mesiánico, para llevar la Torah a su realización destruyéndola de principio a fin" (Agamben, 2000, p. 134). también su indeterminación es imposible, porqueno se ha liberado, ni siquiera al renunciar, delasficcioneshumanas. Noeselhombre de la potencia pura de Agamben ni el Cristo de Deleuze. Su contingencia es abatida en el mismo momento en que la ha conseguido, acaso por lo que ya ha forjado el mundo de los hombres en él o lo que sigue forjando. De cualquier manera, la pérdida de toda identidad no le ha entregado el absoluto (o la nada). La identidad, el universo, el tiempo, el espacio son ficciones, pero ficciones que existen, que han sido creadas, construidas y soñadas, y su existencia ha hecho imposible la vida de Bartleby, el hombre indeterminado. El escribiente no puede llamar a un espacio de heterotopías, de comunidades por venir, de liberación. Devela un mundo de ficción, de representación, pero detrás no hay sino caos. La imposibilidad del mundo utópico que podría adjudicársele, el del mundo sin hombre, lo arroja al absoluto rechazo de todo lo humano.

Bartleby es todos los hombres, porque su actitud nada tiene que ver con el Wall Street del siglo XIX, ni con el mundo modernizado, ni con las leyes de ese tiempo, ni con el capitalismo, ni con la monotonía. Bartleby es todos los hombres, porque su actitud se enfrenta a todos los mundos donde el hombre ha existido y existirá, pues ninguno se ha salvado de la construcción humana que ha impedido la vida sin referencias. En cualquiera de los mundos posibles, el escribiente causaría el malestar que causa en la oficina de Nueva York, aunque de seguro corriera con menos suerte en la mayoría, donde los abogados y los padres parecen menos estúpidos y más maquiavélicos. Bartleby es el no-encasillable, el que está por fuera de todas las categorías, y por 
eso puede ser cualquiera, porque su identidad está vaciada, no se identifica con nada. Esa es la potencia de Bartleby, pero nunca una potencia que se opone al acto. Es una potencia que también prescinde de la oposición entre potencia y acto, y de la misma potencia y la potencia de no. No es un ser puramente en potencia, sino un ser y no ser en potencia (entiéndase también "potencia de no") ${ }^{6}$.

En lo indeterminado de Bartleby no hay nada latente, porque lo indeterminado se ha tornado imposible. Bartleby no anuncia nada que no sea la develación y la falsedad de todas las ficciones humanas (y así el caos) y su terrible consecuencia: la imposibilidad del mundo sin hombre. Toda la humanidad está condenada porque el escribiente ha muerto (y en ese sentido debe morir; mejor: no puede no morir. No se trata de imaginar un happy ending). Bartleby, que al renunciar a todas las ficciones humanas se ha hecho todos los hombres, se ha convertido en el indeterminado, el ser en potencia, que puede y puede-no cualquier cosa; se vuelve, al mismo tiempo, el indeterminado imposible, aquel que renunciando no se ha podido liberar y no puede sino morir; y dejar de participar de la gran farsa humana solo puede llevar al caos:

El código de signos cotidianos le pone unos límites inadmisibles a las fuerzas de la vida, pero la entrega a esas fuerzas fuera del poder de la memoria, que establece la coherencia interior de cada quien consigo mismo, no puede conducir más que a la desintegración en la locura (García Ponce, 1981, p. 54).

6 No es, pues, el casi-Dios que proponía Agamben en su ensayo.
¿Es acaso la memoria lo que hace imposible la vida sin hombre? Bartleby muere porque recuerda, porque reconoce las ficciones humanas (y en ese sentido "no está loco"; veremos ya en qué consiste, entonces, su caos). Renuncia a ellas, pero no puede liberarse. Y así, el hombre que lo podría todo tanto como el poder no, solo puede morir. Aquel que se entrega a las fuerzas de la vida dentro del poder de la memoria no puede enloquecer, tampoco puede vivir entre los hombres.

\section{IV}

En el cuento asistimos a la definitiva perdición de Bartleby, que todavía no ha ocurrido. Cuando empieza el cuento, él todavía copia. Copiar es a lo único que no aplica su famoso "preferiría no hacerlo". Ni siquiera al final, cuando deja de hacerlo, pues dice: "I have given up copying". Sin embargo, esta frase tampoco nos consuela: ¿no puede copiar? ¿No quiere? Su renuncia se escapa de nuevo a toda referencia humana posible. Bartleby es la negación, pero una negación que niega tanto la negación como la afirmación, una negación por fuera de la oposición negación/afirmación. Bartleby está rechazando todos los mundos, hasta el último que le quedaba: copiar. El escribiente no está aquí para liberarnos del pasado certero, para negar el pasado certero. No está para negar el presente (como pretende Agamben). Ni siquiera está para negar el tiempo. Su proceso es doble: evidencia la ficción que es el tiempo, pero sabe que esa ficción existe y nos condena, aunque él deje de participar de ella. Sabe que escribir y vivir como hombre es también una ficción, $\mathrm{y}$ nos condena, aunque se renuncie a escribir 
y vivir. Porque la única ética posible de la escritura es repetir insistentemente en que no se puede escribir, que escribir es imposible. Ya Borges (1957) anunciaba en Discusión cierta poética al respecto:

\section{Releo estas negaciones y pienso: ignoro si la música sabe despertar de la músi- ca y si el mármol del mármol, pero la literatura es un arte que sabe profetizar aquel tiempo en que habrá enmudeci- do, y encarnizarse con la propia virtud y enamorarse de la propia disolución y cortejar su fin (p. 50).}

Y donde los críticos de Flaubert se desconcertaban, Borges veía un símbolo: "El hombre que con Madame Bovary forjó la novela realista fue también el primero en romperla. Chesterton, apenas ayer, escribía: 'La novela bien puede morir con nosotros'” (Borges, 1957, p. 142).

¿Qué tiene que ver esto con la política? Que esa postura está diciendo también que $v i$ vir es imposible, que todas las formas humanas se han encargado de permitirnos lo imposible, de hacernos pasar lo imposible por posible, de hacernos olvidar que no es posible en cuanto verdad la vida humana, el mundo de la representación; $y$, por tanto, de permitirnos la vida humana, hacernos creer que lo que vivimos es la vida verdadera. Y mucha literatura también se ha inscrito allí, igual que el arte. Bartelby no; Bartleby hace parte de la política del caos que recuerda que la vida verdadera es imposible, inclusive la vida de lo indeterminado, de lo que no responde al ser ni al no ser. Todas las formas humanas hacen imposible la única vida posible: la vida por sí misma, la vida sin hombre, sin referencias, sin ser ni no ser.
Llamar pesimista a la política del caos sería caer de nuevo en un juego de opuestos que Bartleby evidencia y hace fracasar. No hay manera de salvar al escribiente. El abogado podrá recurrir a cualquiera de los supuestos humanos, a los más nobles, a su filantropía; pero el espacio en el que Bartleby se ha inscrito no puede responder a ninguno, porque es un no-espacio, sabe que los espacios hacen parte de las construcciones humanas que nada tienen que ver con la vida (y que ese espacio/no-espacio de la vida es inalcanzable por la existencia del espacio del hombre). El torpe abogado incluso llega a pensar que cuando Bartleby lo reconoce en la cárcel y le dice "lo conozco y no tengo nada que decirle" (Melville, 2008, p. 107), es porque lo culpa de haberlo enviado a la cárcel. Bartleby no tiene nada que decirle a nadie. No culpa al abogado menos que lo que podría culpar a todos los hombres. De igual manera, la cárcel es tan buen o mal lugar como lo era la oficina o la calle ("Mire, ahí está el cielo, y aquí el césped" [p. 107], le dice el abogado tratando de consolarlo). Bartleby nos ha dicho que no hay nada que decir ni que hacer en sus pocas palabras $\mathrm{y}$ en sus pocos actos, que se nos aparecen como casi-no-palabras y casi-no-actos.

Tampoco la última hipótesis (Bartleby $\mathrm{y}$ su antiguo empleo en la Oficina de Cartas Muertas de Washington) del abogado nos dice algo del escribiente. No importa qué haya causado la negativa de vida de Bartleby que dentro de su mundo se ha convertido en el agente del caos. No importa si trabajó entre cartas muertas, si murió su amada, si de pequeño algún trauma familiar lo hizo vagabundo ${ }^{7}$. Podemos, incluso,

7 Encontrar una razón así es la eterna confianza del mundo de la representación. Para que alguien enloquezca, para que alguien salga de 
pensar que Bartleby buscó refugio en alguna de las ficciones de los hombres: Dios, un amor, el poder. No importa. También allí fue descubriendo la falsedad de todo, $y$ en el estado en que lo encontramos en el cuento se enfrenta a la imposibilidad de participar de juego humano alguno, y cómo los juegos humanos no le permitirán jamás la posibilidad de la vida sin referencias, la vida sin hombre. En el prólogo de Vive si puedes, García Maffla (1997) parece recalcar esta apreciación sobre la literatura:

\section{Libro dedicado a la realidad del poema como plasmación de la imposibilidad y de la desesperanza. El título viene de una idea de Rilke, que comparto como ninguna otra de nadie, y que reza "Vi- vir es imposible, y la tarea del hombre consiste en sobreponerse" (p. 3).}

Bartleby es esa literatura, es la política del caos, porque nadie sabe qué hacer con él, nadie sabe dónde encasillarlo, nadie sabe cómo tratarlo, a qué apelar cuando están frente a él: olvidan cómo actuar. Revisemos los pasajes en el cuento. El abogado dice:

Cuando a una persona se le lleva la contraria con contundencia y sin que medie motivo alguno, no es raro que esta empiece a dudar de sus convicciones más elementales. Empieza a plantearse, por así decirlo, la remota posibilidad de que la justicia y la razón estén de parte del otro (Melville, 2008, p. 47).

ese mundo, siempre se buscan justificaciones, algo tiene que haber pasado. No es posible, no quiere que sea posible, para el mundo de los hombres, que alguno se aparte porque lo ha encontrado falso, que haya encontrado en las pequeñas irracionalidades su irrealidad.
Y agrega: "La pasividad de Bartleby llegaba a veces a irritarme" (p. 26); "Y temblaba de pensar que mi trato con el escribiente había afectado ya, y seriamente, mi estado mental" (p. 36). Podemos recordar también al abogado en la calle, suponiendo que la gente apuesta sobre si el escribiente se irá o no; la palabra prefer, que los demás empleados empiezan a usar sin darse cuenta; el escándalo que genera entre los inquilinos del edificio por no saber qué hacer con él; el "aire de tristeza" que ha derramado sobre el local del abogado, etc. Su caos no genera el mundo indeterminado en el que él se encuentra $^{8}$, sino un caos como alteración del mundo de referencias: dudas, opuestos que se intercalan, convicciones que se cuestionan, inclusive hombres de razón que ahora rayan en la idiotez. En una palabra: incertidumbre. Bartleby es inmune a la razón, pero también a la fe, a la compasión, al dinero, a la ambición, al hombre y al hambre ${ }^{9}$.

Esto enloquece a cualquiera. Esto empieza a generar el caos. Bartleby se convierte en el hombre intuitivo del que hablaba Nietzsche (1998) en Sobre verdad y mentira en sentido extramoral:

8 Aunque por un instante, y nada más, logra hacerlo con el abogado luego del segundo "preferiría no hacerlo": "Por algunos momentos me convertí en una estatua de sal, a la cabeza de mi columna de amanuenses sentados" (Melville, 2008, p. 45).

9 No se suicida porque esa sería una preferencia, porque está más cerca de lo que escribía Fernando Pessoa (2010) en El libro del desasosiego: "Me sucede a veces, y siempre que me sucede es casi de repente, que me aparece en medio de las sensaciones un cansancio tan terrible de la vida que es imposible imaginar un acto con el qué dominarlo. Para remediarlo, el suicidio parece poco seguro, la muerte, incluso presupuesta la inconsciencia, todavía poco. Es un cansancio que ambiciona no el dejar de existir - cosa que puede ser posible o puede no serlo-, sino una cosa mucho más horrorosa y profunda, el dejar de ni siquiera haber existido, lo que no hay modo de que pueda acontecer" (p. 155) 
Confunde [el hombre intuitivo] sin cesar las rúbricas y las celdas de los conceptos introduciendo de esta manera nuevas extrapolaciones, metáforas y metonimias, continuamente muestra el afán de configurar el mundo existente del hombre despierto, haciéndolo tan abigarradamente irregular, tan inconsecuente, tan encantador y eternamente nuevo, como lo es el mundo de los sueños (p. 22).

Cuando Borges compara a Bartleby con Moby Dick, en su prólogo de 1979, dice: “Las 'simpatías', acaso más secretas, están en la locura de ambos protagonistas y en la increíble circunstancia de que contagian esa locura a cuantos los rodean" (en Melville, 2008, p. 15). Y en el prólogo de 1944 señala:

El cándido nihilismo de Bartleby contamina a sus compañeros y aún al estólido señor que refiere su historia y que le abona sus imaginarias tareas. Es como si Melville hubiera escrito: Basta que sea irracional un solo hombre para que otros lo sean y para que lo sea el universo. La historia universal abunda en confirmaciones de ese tenor (en Melville, 2008 , p. 12$)^{10}$.

El fracaso de un solo libro es el fracaso de toda la literatura; el fracaso de un solo hombre es el fracaso de toda la humanidad. Ese es el caos que Bartleby genera; esa es su política, su ética.

10 Lo confirma Borges (1957) en otro ensayo: "Para escarnecer los anhelos de la humanidad, Swift los atribuyó a pigmeos o a simios. Flaubert, a dos sujetos grotescos. Evidentemente, si la historia universal es la historia de Bouvard y de Pécuchet, todo lo que la integra es ridículo y deleznable" (p. 143).
La política del caos no es la de la inactividad, pues de nuevo sería encasillar la renuncia de Bartebly como una renuncia a la acción, como si optara o "prefiriera" la inacción. Y así, Bartleby se inscribe en la lista de personajes a quienes un hecho dentro de la vida humana los arroja a lo indeterminado y se les hace imposible vivir, actuando o no, contraria a aquella lista de perezosos e inactivos en la que muchos lo han incluido. Su actitud se escapa también de la oposición entre actuar y no actuar e inclusive entre la de querer actuar o no quererlo. Sus decisiones o falta de decisiones, sus acciones o falta de acciones, nada tienen que ver con la voluntad, la necesidad, ni siquiera la posibilidad.

De esta manera, Bartleby no es primo de Akakij Akakievic, ni del príncipe Miskyn, sino del personaje de La Carta de Lord Chandos y José Arcadio Buendía en Cien años de soledad; del artista del hambre de Kafka, del Wakefield de Howthorne, del hombre de "La tercera orilla del río", el cuento de João Guimarães Rosa. También el cine abunda en estos personajes: el niño de Alemania año cero (de Roberto Rossellini) en los últimos quince minutos de película, los personajes de Dolls (de Takeshi Kitano), los jóvenes asesinos en Elephant (de Gus Van Sant), la empleada en La ceremonia (de Claude Chabrol). Sin embargo, en el caso de ellos está claro qué los ha llevado a ese estado. Lord Chandos nos narra cómo descubrió el absurdo del lenguaje; José Arcadio es visitado por un viejo fantasma y se da cuenta de que todos los días son iguales a los otros (me llama la atención este caso, pues todos 
catalogan a José Arcadio como "loco", aunque ha llegado a su estado por un detenido análisis de la realidad); al artista del hambre no le gusta ninguna comida ${ }^{11}$; el niño de Alemania año cero ha matado a su padre; los jóvenes de Elephant llevan una vida de perdedores en el colegio. Tal vez por eso esté Bartleby más cercano a Justine en Melancholia (de Lars Von Trier) o al joven en We Need to Talk about Kevin (de Lynne Ramsay), donde nunca se sabe exactamente a qué se debe la tristeza absoluta y la imposibilidad de vivir de la protagonista, en el primer caso, y al odio y violencia del joven, en el segundo. También ellos son un agente del caos. Son personajes cuya potencia no radica en absoluto en la voluntad. Ninguno ha elegido el odio, la locura, la inacción, la melancolía. Sus estados no pasan por la voluntad, y ni el más optimista llegará a pensar que se pueda apelar a esta cuando se les pida salir de allí. Agamben (2000) ("Bartleby cuestiona precisamente esta supremacía de la voluntad sobre la potencia" [p. 112]) y Deleuze (2000) ("nada de voluntad mejor que voluntad de nada" [p. 76]) lo reconocen. Bartleby, sin embargo, brilla entre todos por lo primordial de su inadvertencia.

La política del caos dice que no hay política ni ética posible, que no hay escritura ni vida posible. Cualquier política (inclusive una por-venir) sería una nueva ficción. Cualquier ética, cualquier escritura, también. La única vida posible, la vida sin referentes,

11 "Y si alguna vez alguien le compadecía y argumentaba que probablemente su tristeza se debía al hambre, no era infrecuente, sobre todo si estaba ya muy avanzado el ayuno, que el ayunador respondiera con una explosión de furia ante el espanto general, sacudiendo como una fiera los barrotes de la jaula" (Kafka, 1983, p. 81). Otra vez los demás giran alrededor de este tipo de personajes buscando una razón del sistema de referencias para explicar lo inexplicable. sin hombre, sin ser ni no-ser, ha sido anulada por las ficciones existentes (nótese que no se trata de negar la existencia, es precisamente la existencia de lo ficcional lo que permite el proceso de Bartleby). Tal vez no haya nada más que decir al respecto que lo que Blanchot (1990) ha sentenciado sobre Bartleby:
"Preferiría no" pertenece al infinito de la paciencia, no da pie a la intervención dialéctica: hemos caído fuera del ser, en el campo de lo exterior por donde, inmóviles, andando parejo y despacio, van y vienen los hombres destruidos (p. 22).

Y estas líneas finales de Hawthorne en uno de sus cuentos más famosos, que encajan en Bartleby perfectamente:

\begin{abstract}
En el desorden aparente de nuestro misterioso mundo, cada hombre está ajustado a un sistema con tan exquisito rigor $-\mathrm{y}$ los sistemas entre sí, y todos a todo- que el individuo que se desvía un solo momento, corre el albur de perder para siempre su lugar. Corre el albur de ser, como Wakefield, el Paria del Universo (en Borges, 2001, p. 59).
\end{abstract}

\section{Referencias}

Agamben, G. (2000). Bartleby o la contingencia. En Preferiría no hacerlo. Valencia: Pre-Textos. Blanchot, M. (1990). La escritura del desastre. Caracas: Monte Ávila.

Borges, J. L. (1957). Discusión. Buenos Aires: Emecé. 
Borges, J. L. (2001). Otras inquisiciones. Bogotá: El Tiempo.

Deleuze, G. (2000). Bartleby o la fórmula. En Preferiría no hacerlo. Valencia: Pre-Textos.

García Maffla, J. (1997). Vive si puedes. Medellín: Editorial Universidad de Antioquia.

García Ponce, J. (1981). La errancia sin fin: Musil, Borges, Klossowski. Barcelona: Anagrama.

Kafka, F. (1983). La metamorfosis y otros relatos. Bogotá: La Oveja Negra.
Melville, H. (2008). Bartleby (traducción y prólogos de Jorge Luis Borges). Rosario: Serapis.

Nietzsche, F. (1998). Sobre verdad y mentira en sentido extramoral. Madrid: Tecnos.

Pessoa, F. (2010). El libro del desasosiego. Barcelona: Acantilado.

Rancière, J. (2004). Deleuze, Bartleby, and the literary formula. En The flesh of words. California: Standford University Press. 